\title{
Consumer perceptions of food safety of fried mussel: multiple correspondence analysis
}

\author{
Demet Kocatepe $^{1} \mathbb{D}^{\mathbb{D}}$, B. Barış Alkan² ${ }^{\mathbb{D}}$, İrfan Keskin ${ }^{1}$ (D), Yalçın Kaya ${ }^{1}$ (D)
}

Cite this article as:

Kocatepe, D., Alkan, B.B., Keskin, İ., Kaya, Y. (2020). Consumer perceptions of foods safety of fried mussel: multiple correspondence analysis. Food and Health, 6(1), 9-19. https://doi.org/10.3153/FH20002

${ }^{1}$ Sinop University, Faculty of Fisheries, Department of Fish Processing, 57000, Sinop, Turkey

${ }^{2}$ Akdeniz University, Department of Educational Sciences, 07058, Antalya, Turkey

ORCID IDs of the authors:

D.K. 0000-0002-9234-1907

B.A. 0000-0002-5851-7833

İ.K. 0000-0003-4503-7299

Y.K. 0000-0002-1259-2336

Submitted: 25.04 .2019

Revision requested: 14.07 .2019

Last revision received: 25.07 .2019

Accepted: 01.08.2019

Published online: 25.11 .2019

Correspondence:

Demet KOCATEPE

E-mail: demetkocatepe@hotmail.com

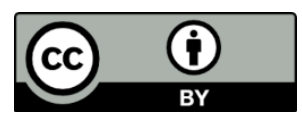

CCopyright 2020 by ScientificWebJournals Available online at

http://jfhs.scientificwebjournals.com

\begin{abstract}
The conscious society has begun to be more selective about food and the interest in traditional food has increased. Ready to eat foods are sold even on traditional food streets and food safety has been questioned. In the scope of the study, food safety of the fried mussel consumed is investigated. This study aims to evaluate food safety perceptions of fried mussel consumers through a survey conducted in Sinop which is a province of Turkey. Data were collected through a face-toface survey and 234 respondents joined our research. Multiple correspondence analysis methods were selected to find out the food safety perception of customers.

As a result of research, it was determined that of respondents under the age of 30 don't have knowledge about food safety, but respondents over the age of 30 have knowledge about food safety. Also, the respondents in the $45+$ age group think that fried mussel is healthy, while the 30 44 age group clearly think that they are not healthy. Overall respondents have different views of different sea products consumption, sales locations, hygienic conditions, and food safety.
\end{abstract}

Keywords: Food safety, Fried mussel, Ready to-eat food, MCA (multiple correspondence analysis) 


\section{Introduction}

The consumption of processed food, which has food additives, has increased with the rapidly increasing world population. However, technological developments have increased consumer awareness, especially in food products that directly related to our health. Every day people started to move away from refined and fast food products, traditional foods became important. Anxieties about people's healthy life increase traditional food consumption and demand. Food safety is generally a healthy and reliable way of delivering food to the consumer by preserving the chemical, physical, sensory and microbiological qualities of the food, from the production to the consumption (from farm to fork).

As the preference of traditional products increases, quantitative studies (Ohiokpehai 2003; Bindu et al. 2004, 2007, 2014; Turan et al. 2015; Kocatepe et al. 2016; Steyn et al. 2013; Marras et al. 2014; Alfiero et al. 2017) on the safety of these foods and particularly qualitative (Taşdan et al. 2014; Kocatepe and Trrıl 2015; Şahin and Meral 2012; Gülse Bal et al. 2006) studies that have overlooked consumer opinions have increased.

Mussel meat consumed as raw, canned, smoked, marinated, dried, frozen throughout the world. In Turkey, mussel stuffed and fried mussel consumed especially in coastal areas are the most preferred mussel products. The fried mussel is usually prepared at homes and restaurants. It is offered to people's consumption through street vendors and restaurants. However, cleaning and preparation steps are quite laborious and time consuming. In addition, shelf life of mussel is very limited and the presence of mussels is seasonal. These problems make it difficult for consumers to buy this food. The fried mussel contains $42.62 \%$ moisture, $22.94 \%$ protein, $30.14 \%$ fat and 4.6\% ash (Bindu et al. 2004). Kocatepe et al. (2019) had reported the fried mussel's crude protein, crude lipid, moisture, and crude ash as 13.94-16.72, 6.76-11.37, 72.19$56.99,5.12-9.76 \%$ respectively. And they reported that the frying methods were effect the proximate compositions of mussels. The mussel water activity ranges from 0.85 to 0.92 (Bindu et al., 2004). The chemical and microbiological spoilage of the mussel which has high water activity, is very rapid. For this reason, the mussels are kept alive in the water before being processed, and then the shells of mussels removed, immersed in carbonated water. Then mussels are covered with $\operatorname{mix}$ (flour + salt + spice) and fried in hot deep oil. After this process; fried mussels consumed immediately. For this reason, fried mussels are a traditional food among street foods. Street foods are ready-to-eating food items retailed by vendors and can be snacks, main meals or beverages (Ohiokpehai 2003). Street foods come with many advantages, they are usually cheap, are easily available at everytimes and places and are often the only business catering to the working poor urban population. However, their doubtless positive character, the dominant role that street foods play in the nutrition of many urban dwellers comes with many challenges. Unsanitary conditions, bad food quality and pollution are just some of the negative aspects of street foods that emerged during this discussion. However, these big challenges, there seems to be little doubt among the participants to this discussion however, that street foods are part of urban life and that this thriving sector and those active in it are well worth being protected and supported. As one of the major means foraccessing food for the urban population, street food should get more attention by governmentsand development agents in order to improve their status and their impact on food security, food safety and nutrition (FAO, 2011).

In recent years, it has been observed that in the public opinion surveys, it is preferred to use data analysis methods which enable people's demographics as well as perceptual characteristics to be represented with points in the multi-dimensional space. It is highly relevant to determine the geometric positions of observations and features through the use of similarity or difference information based on distance measures in terms of certain characteristics of observations. When the studies done for this purpose are examined, in the analysis of the categorical data, the most frequently used multiple correspondence analysis (MCA) method is encountered. MCA is a generalization of the simple correspondence analysis (CA) method of multivariate categorical data called Burt matrix. Greenacre and Blasius (1994) described in detail the computations involved in CA. A multiple correspondence map makes it easier to interpret the relationships in the correspondence table (Greenacre and Blasius, 2006).

This study aims to evaluate food safety perceptions of fried mussel consumers through a survey conducted in Sinop which is a province of Turkey. Data was collected through a face-to-face survey and 234 respondents participated in this research. Multiple correspondence analysis methods were selected for find out the food safety perception of customers.

\section{Materials and Methods}

\section{Data Collection}

The data have been collected using face to face survey method in Sinop which is a small city on the most northern edge of the Turkish side of the Black Sea coast in the period between June and August 2017. Survey were applied to consumers, where fried mussels were sold. The surveys consist of twenty-one questions. The survey questions (Table 1) developed by us were below: 
Table 1. Survey questions

\begin{tabular}{ll}
\hline & \multicolumn{1}{c}{ Demographic profile questions $(\mathbf{Q})$} \\
\hline Q1 & Gender \\
Q2 & Age \\
Q3 & Marital Status \\
Q4 & Occupation \\
Q5 & Income \\
Q6 & Educational Level \\
Q7 & Nationality \\
\hline
\end{tabular}

\section{Yes / No questions}

Q8 Do you have information about food safety?

Q10 Do you have seafood that you consumed other than fish?

Q11 Do you have information about mussel?

Q13 Have you ever eat fried mussel before?

Q18 Do you have any fear about consuming mussel?

Q20 Have you ever been gastro -intestinal diseases after you consumed fried mussel?

Q21 Is the fired mussel healthy?

\section{Multiple choice questions}

Q9 What is the food safety? (you can mark more than one answer)

Q12 Which mussel product do you prefer to eat?

Q14 How often do you consume fried mussel?

Q15 Which hour intervals do you eat fried mussel?

Q16 Where do you buy a fried? Or Where do you eat a fried mus-

sel?

Q17 What is the most important thing for you in terms of food safety when buying fried mussel?

Q19 What is your information resource about the fried mussel security?

Data from 234 consumers who responded to the questionnaires were evaluated.

\section{Multiple Correspondence Analysis (MCA)}

Correspondence analysis is an exploratory technique used to analyze categorical data tables.

If there are more than two categorical variables in the correspondence table, multiple correspondence analysis which is the generalization of simple correspondence analysis, is used. The simplest way of the generalization of simple (two categorical variable) correspondence analysis to the multivariate case is to apply the correspondence analysis to a matrix, often denoted G, called the indicator matrix (Greenacre, 1988). Indicator variables are constructed for each category of variables.
In the case of $X$ variables, $x$ the category number of the variable is $\mathrm{p}_{\mathrm{x}}$ while the total category number is denoted by $\mathrm{P}$ in all the variables.

$\mathrm{P}=\sum_{\mathrm{X}=1}^{\mathrm{X}} \mathrm{p}_{\mathrm{X}}$

The $\mathrm{G}$ indicator matrix, in which $\mathrm{n}$ responses are defined in binary code, is a matrix of indicator variables. $G$ matrix is a matrix consisting of ' 0 ' and ' 1 ' values. If an observation falls into the category of $p, G_{i p}=1$, otherwise $G_{i p}=0$ (Greenacre, 1988). In another form, the $G$ matrix is formed by writing the $\mathrm{X}$ submatrices side by side.

$$
\mathrm{G}=\left(G_{1}, G_{2}, \ldots, G_{x}, \ldots, G_{X}\right)(2)
$$

The matrix obtained by multiplying the transpose of the indicator matrix by itself is called the Burt Matrix. Burt Matrix is indicated by ' $\mathrm{B}$ '.

$$
B=G^{T} G(3)
$$

Burt Matrix is a symmetric and square matrix. Multiple correspondence analysis can be defined as simple correspondence analysis of the Burt Matrix (Greenacre and Blasius, 1994).

To obtain MCA from matrix B, the following steps are performed.

Step 1. Correspondence matrix $\mathrm{P}$ is obtained as

$\mathrm{P}=\left\{\mathrm{p}_{\mathrm{ij}}\right\}=\mathrm{b}_{\mathrm{ij}} / \mathrm{n}$

where $n=\sum_{i, j} b_{i j}$, also, row totals ( $\mathrm{r}_{\mathrm{i}}$ ) equal to column totals $\left(r_{j}\right)$.

Step 2. Standardized residuals matrix $\mathbf{S}$ is abtained and performed an eigenvalue-eigenvector decomposition on $\mathrm{S}$.

$\mathrm{S}=\left\{\mathrm{s}_{\mathrm{ij}}\right\}=\left(\mathrm{p}_{\mathrm{ij}}-\mathrm{r}_{\mathrm{i}} \mathrm{r}_{\mathrm{j}}\right) / \sqrt{\mathrm{r}_{\mathrm{i}} \mathrm{r}_{\mathrm{j}}}$

The eigenvectors, $v_{i j}$ and the eigenvalues, $\lambda_{s}$ are obtained by an eigenvalue-eigenvector decomposition of S. $\lambda_{s}$ values are principal inertias of $\mathrm{G}$. If we want to find the principal inertias of $\mathrm{B}$, these values are squared.

Step 3. The standard coordinate for i-th row (or column) in the s-th dimension is obtained as

$t_{i s}=v_{i s} / \sqrt{r_{i}}$

Step 4. The principal coordinates are foundby

$f_{i s}=t_{i s} \lambda_{s}$

In this study, SPSS statistical package program was used for data analysis. More information about MCA can be found in Benze'cri 1969,1992; Hill 1974; Nishisato 1980,; Nishisato 
and Sheu 1980; Young 1981; Greenacre and Blasius 1994; Weller and Romney 1990; Clausen 1998; Greenacre and Blasius 2006; Abdi and Valentin 2007; Le Roux and Rouanet 2010; Husson and Josse 2014; Greenacre 2017; Husson et al. 2018.

\section{Results and Discussion}

A total of 234 respondents are interviewed. Approximately $59 \%$ of them is male and $41.5 \%$ is female. Large number of respondents were aged between 19 and 44 (83.3\%). 68.8\%of the respondents works full-time, $31.2 \%$ of the respondents is not working any job and student. Occupations of the respondentswork official $(22.2 \%)$, engineer or doctor $(16.2 \%)$, labourer (13.7\%), student (26.5\%) and other (16.7\%). Table 2 summarized the demographic data of respondents. This study examined the validity of MCA method. The output of MCA includes plots of the category quantifications and the object scores.

According to income group (under TL (Turkish liras) 1000, TL 1001-2500, TL 2501-4000, above TL 4000) and occupation (not working, official, engineer or doctor, labourer, student, other) the relationship between "What is the most important thing for you in terms of food safety when buying fried mussel?" (Hygienic preparation, sales and service; Personal hygiene; Selling area; Taste; Experiences; Freshness; Price), and "Have you ever been gastro-intestinal diseases you consumed fried mussel?" (Discomfort; No Discomfort) variables were analysed by multiple correspondence analysis. Figure 1 shows the symmetric map of these categories.

If we examine the amounts of inertia and their percentages which each axis have, the first horizontalaxisis of, accounting for $35.9 \%$ of the inertia, and the second is of accounting for $34.4 \%$ of the total inertia, so the essential information is captured by the horizontal and vertical spread of the points in two dimensions.
Table 2. Demographic profile of respondents in the conducted survey

\begin{tabular}{|c|c|c|}
\hline Parameters & $\begin{array}{l}\text { Number of } \\
\text { respondents }\end{array}$ & Percent (\%) \\
\hline \multicolumn{3}{|l|}{ Gender } \\
\hline female & 97 & 41.5 \\
\hline male & 137 & 58.5 \\
\hline total & 234 & 100 \\
\hline \multicolumn{3}{|l|}{ Age } \\
\hline 13-18 years & 17 & 7.3 \\
\hline 19-29 years & 93 & 39.7 \\
\hline $30-44$ years & 102 & 43.6 \\
\hline$>45$ years & 22 & 9.4 \\
\hline total & 234 & 100 \\
\hline \multicolumn{3}{|l|}{ Marital Status } \\
\hline Married & 127 & 54.3 \\
\hline Single & 107 & 45.7 \\
\hline Total & 234 & 100 \\
\hline \multicolumn{3}{|l|}{ Occupation } \\
\hline Not working & 11 & 4.7 \\
\hline Official & 52 & 22.2 \\
\hline Engineer or Doctor & 38 & 16.2 \\
\hline Labourer & 32 & 13.7 \\
\hline Student & 62 & 26.5 \\
\hline Other & 39 & 16.7 \\
\hline Total & 234 & 100 \\
\hline \multicolumn{3}{|l|}{ Income } \\
\hline Under TL 1000 & 20 & 8.5 \\
\hline$T L 1001-2500$ & 62 & 26.5 \\
\hline$T L 2501-4000$ & 83 & 35.5 \\
\hline Above TL 4000 & 69 & 29.5 \\
\hline Total & 234 & 100 \\
\hline \multicolumn{3}{|l|}{ Education Level } \\
\hline Literate & 4 & 1.7 \\
\hline Primary school & 2 & 0.9 \\
\hline Primary education & 4 & 1.7 \\
\hline secondary school & 13 & 5.6 \\
\hline High school & 36 & 15.4 \\
\hline University & 175 & 74.8 \\
\hline Total & 234 & 100 \\
\hline \multicolumn{3}{|l|}{ Nationality } \\
\hline T.C. (Turkish citizen) & 209 & 89.4 \\
\hline Other & 25 & 10.6 \\
\hline Total & 234 & 100 \\
\hline
\end{tabular}




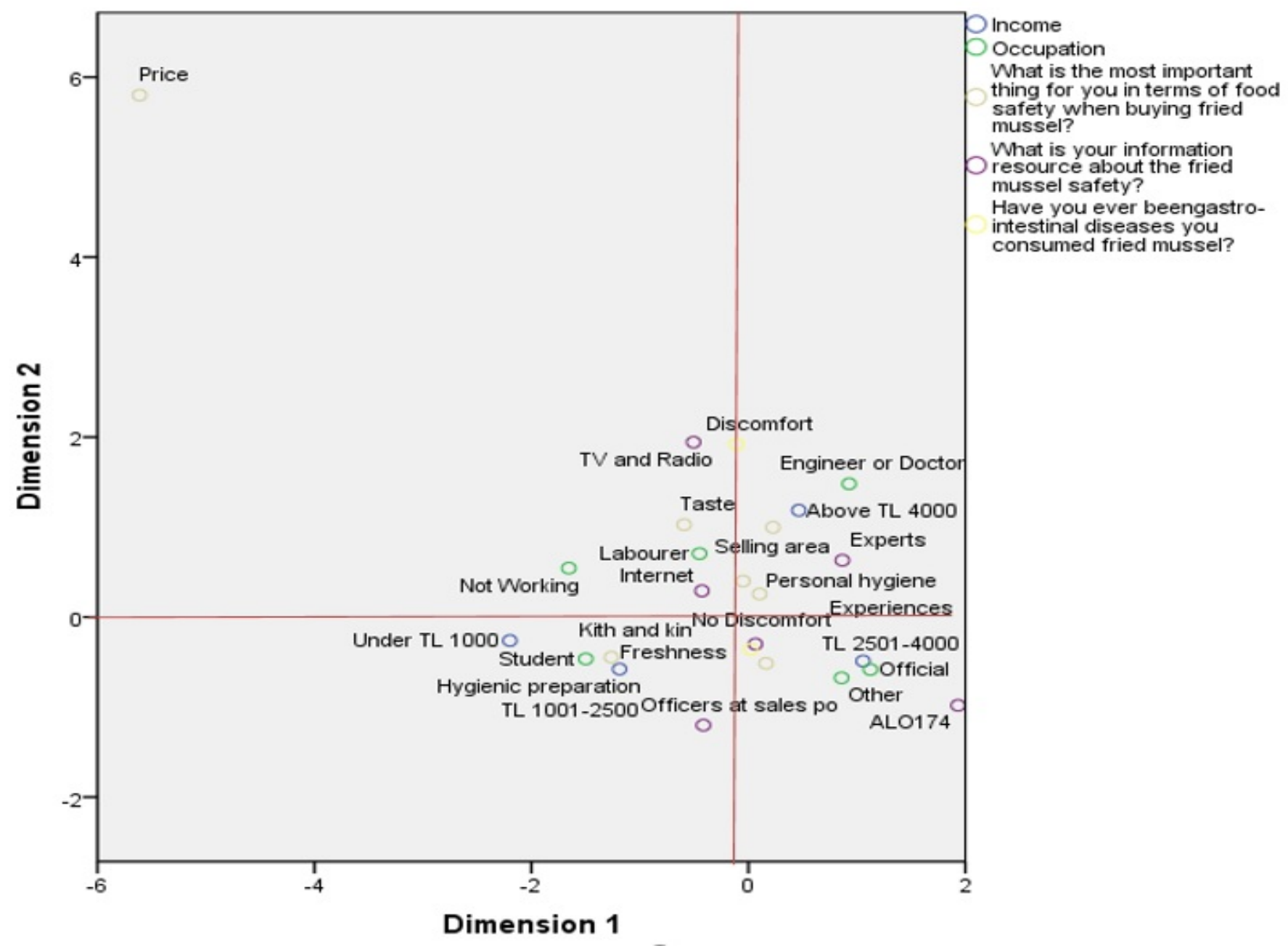

Figure 1. Two dimensional multiple correspondence analysis map for five categorical variables (income, occupation, Q17, Q19, Q20), *Alo 174: Republic of Turkey Ministry of Agriculture and Forestry: Food line, safer food healty life.

Table 3 presents the results of discrimination measures for dimensions and variables. As a result of analysis, the inertia values are obtained by 0.3598 for Dimension 1 and 0.344 for Dimension 2. According to these values, the graphical representation given in Figue 1 can be said to have a good fit between the categories with a total variance ratio of $70.3 \%$. When discreteness measures which are called as squared correlation in Table 2 are examined, it is seen that occupation and income variables contribute a great deal to explain the first dimension, also, in the explanation of the second dimension, it is seen that all variables provide contributions at similar rates.
Table 3. Discrimination measures for dimensions and variables (Occupation, Income, Q17, Q19, Q20)

\begin{tabular}{lcc}
\hline Variables & Dimension 1 & Dimension 2 \\
\hline Occupation & 0.780 & 0.378 \\
\hline Income & 0.750 & 0.347 \\
\hline $\begin{array}{l}\text { Q17. What is the most im- } \\
\text { portant thing for you in } \\
\text { terms of food safety when } \\
\text { buying fried mussel? }\end{array}$ & 0.148 & 0.325 \\
\hline $\begin{array}{l}\text { Q19. What is your infor- } \\
\text { mation resource about the } \\
\text { fried mussel safety? }\end{array}$ & 0.110 & 0.267 \\
\hline $\begin{array}{l}\text { Q20.Have you ever } \\
\text { beengastro-intestinal dis- } \\
\text { eases you consumed fried } \\
\text { mussel? }\end{array}$ & 0.001 & \\
\hline
\end{tabular}


When Figure 1 is examined, it is seen that the respondents participating in the study were influenced by kith and kin as fried mussel safety source of not working and students with income between TL 1000 and TL 1001-2500, and it is generally seen that the hygienic preparation. Also, the respondents who have TL 2501-4000 and above TL 4000 have seen Experts and ALO174 (Republic of Turkey Ministry of Agriculture and Forestry-complaint line) as an information source for fried mussel safety by Engineer or Doctor, Official and Others and personnel hygiene is the most important issue in terms of food safety.Another comment from Figure 1 is that while engineer or doctor,labourer and notworking which is participated in the survey are "Discomfort" after they have consumed fried mussel, students and official are not "Discomfort".

According to age group (13-18 years; $19-29$ years; 30-44 years; $>45$ years). the relationship between "Is the fried mussel healthy?" (YES; NO) and "Do you have information about food safety?" (I have; I don't have) variables were analysed by multiple correspondence analysis. Figure 2 shows the symmetric map of these categories.

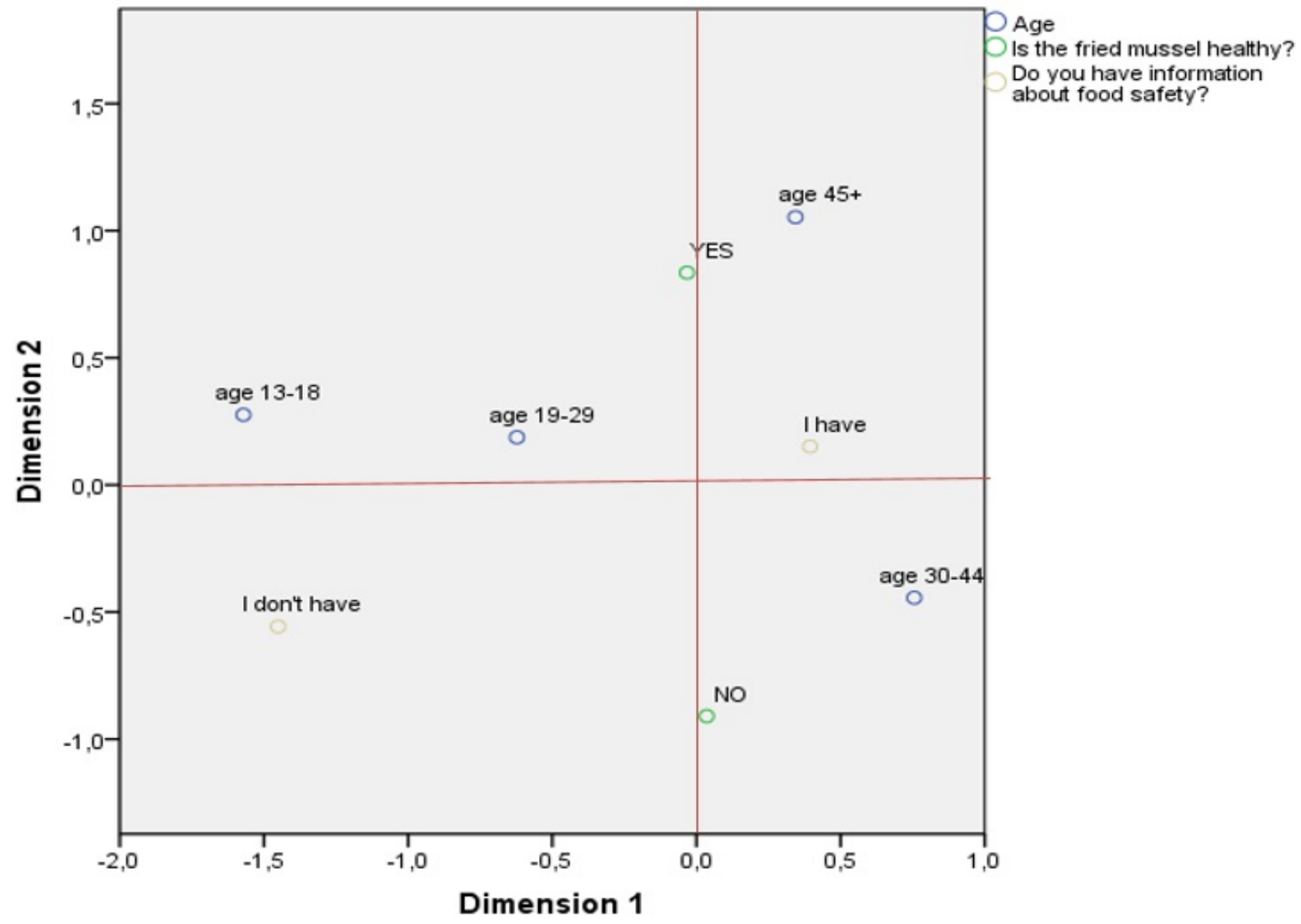

Figure 2. Two dimensional multiple correspondence analysis map for 3 categorical variables (Age, Q8, Q21)

Table 4 presents the results of discrimination measures for dimensions and variables. As a result of analysis, the inertia values are obtained by 0.389 for Dimension 1 and 0.351 for Dimension 2. According to these values, the graphical representation given in Figue 2 can be said to have a good fit between the categories with a total variance ratio of $74 \%$. When discreteness measures which are called as squared correlation in Table 4 are examined, it is seen that age and Q8 variables contribute a great deal to explain the first dimension, also, in the explanation of the second dimension, Q21 is very important variable. It has a great contribution for Dimension 2.

When the graph in Figure 2 is analyzed. it is seen that respondents in the 13-18 age group and 19-29 age group have no information about food safety, but respondents in the 30 44 and $45+$ age groups have knowledge about food safety. Also, the respondents in the $45+$ age group think that fried mussel is healthy, while the 30-44 age group clearly think that they are not healthy. 
Table 4. Discrimination measures for dimensions and variables (Age, Q8, Q21)

\begin{tabular}{lcc}
\hline Variables & Dimension & Dimension \\
& $\mathbf{1}$ & $\mathbf{2}$ \\
\hline Age & 0.593 & 0.210 \\
Q8. Do you have informa- & 0.572 & 0.084 \\
tionabout food safety? & & \\
$\begin{array}{l}\text { Q21. Is the fried mussel } \\
\text { healthy? }\end{array}$ & 0.001 & 0.759 \\
\hline
\end{tabular}

According to nationality (T.C.; Other) the relationship between "Do you have seafood that you consume other than fish?" (YES; NO) and "What is the most important thing for you in terms of food safety when buying fried mussel?" (Hygienic preparation, sales and service; Personal hygiene; Selling area; Taste; Experiences; Freshness; Price) variables were analysed by multiple correspondence analysis. Figure 3 shows the symmetric map of these categories.

Table 5 presents the results of discrimination measures for dimensions and variables. As a result of analysis, the inertia values are obtained by 0.454 for Dimension 1 and 0.380 for Dimension 2. According to these values, the graphical representation given in Figue 3 can be said to have a good fit between the categories with a total variance ratio of $83.3 \%$. When discreteness measures which are called as squared correlation in Table 5 are examined, it is seen that Q10 and Q17 variables contribute a great deal to explain the first dimension, also, in the explanation of the second dimension. Nationality and Q17 are very important variables. They have a good contribution for Dimension 2.

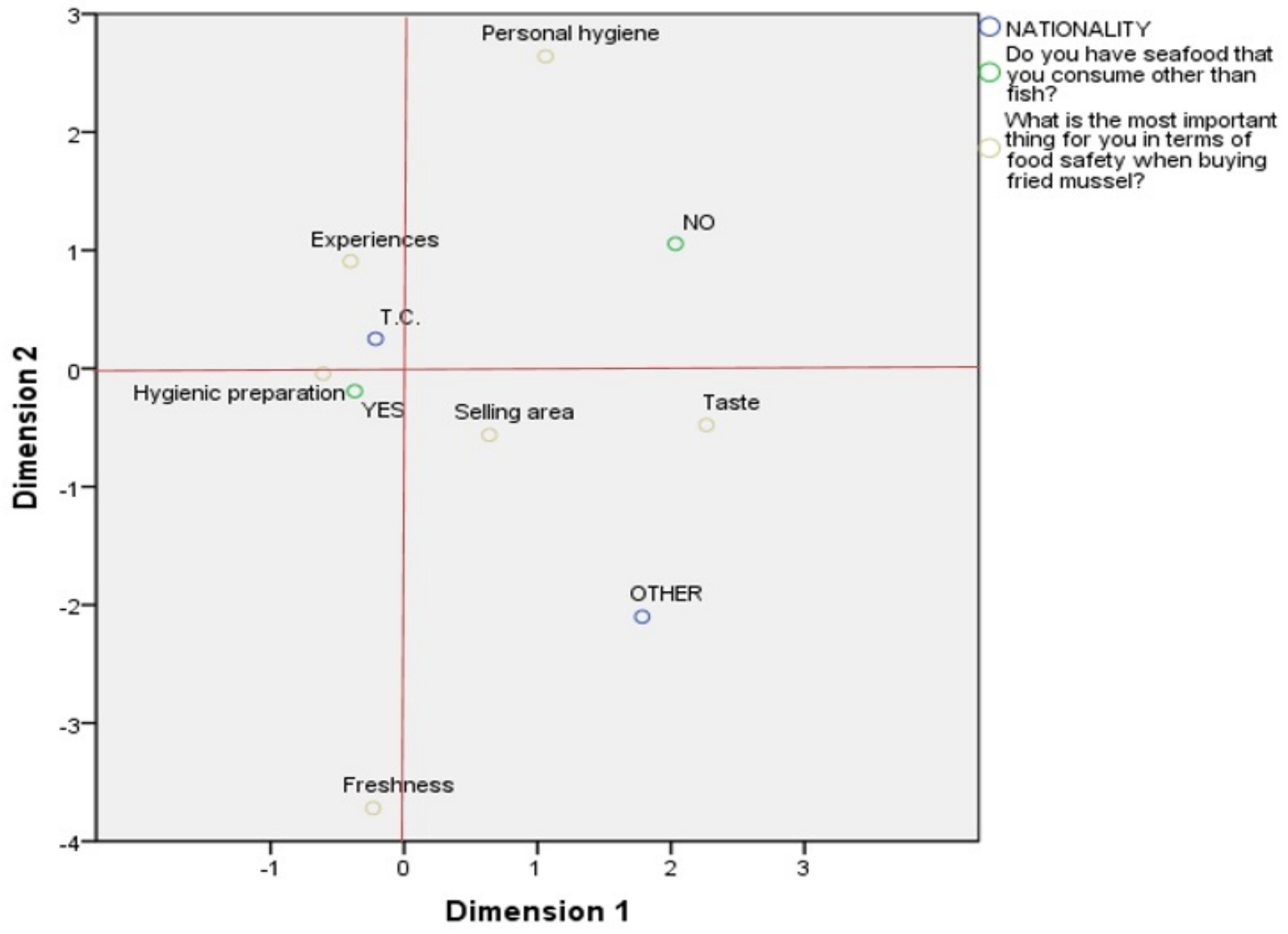

Figure 3. Two dimensional multiple correspondence analysis map for 3 categorical variables (Nationality, Q10, Q17) 
Table 5. Discrimination measures for dimensions and variables (Nationality, Q10, Q17)

\begin{tabular}{lcc}
\hline Variables & Dimension 1 & Dimension 2 \\
\hline Nationality & 0.257 & 0.325 \\
Q10. Do you have seafood & 0.506 & 0.125 \\
that you consume other & & \\
than fish? & & \\
Q17. What is the most im- & 0.598 & 0.689 \\
portant thing for you in & & \\
terms of food safety when & & \\
buying fried mussel? & & \\
\hline
\end{tabular}

When the graph in Figure 3 is examined. Turkish national respondents who say that they have not consumed seafoods that they consumed other than fish before, have paid attention to hygienic preparation, experiences and freshness in terms of food safety. For other (non-Turkish) respondents who say that they do not consume seafoods other than fish, it is seen that personal hygiene, taste and selling area variables are important in terms of food safety. Also, in Figure 3, the personal hygiene and freshness categories seem to be far from the origin. This indicates that the marginal frequencies of these categories are less than the others.

According to occupation (not working, official, engineer or doctor, labourer, student, other). income group (under TL 1000, TL 1001-2500, TL 2501-4000, above TL 4000) and education (literate; primary school; primary education; secondary school; high school; University), the relationship between "Where do you buy a fried mussel? or Where do you eat a fried mussel? "(Home made; Otel; Market; Restaurant; FastFood; Street saler), "What is the most important thing for you in terms of food safety when buying fried mussel?" (Hygienic preparation. sales and service; Personal hygiene; Selling area; Taste; Experiences; Freshness; Price) and "Have you ever been gastro-intestinal diseases you consumed fried mussel?" (Discomfort; No Discomfort) variables were analysed by multiple correspondence analysis. Figure 4 shows the symmetric map of these categories.

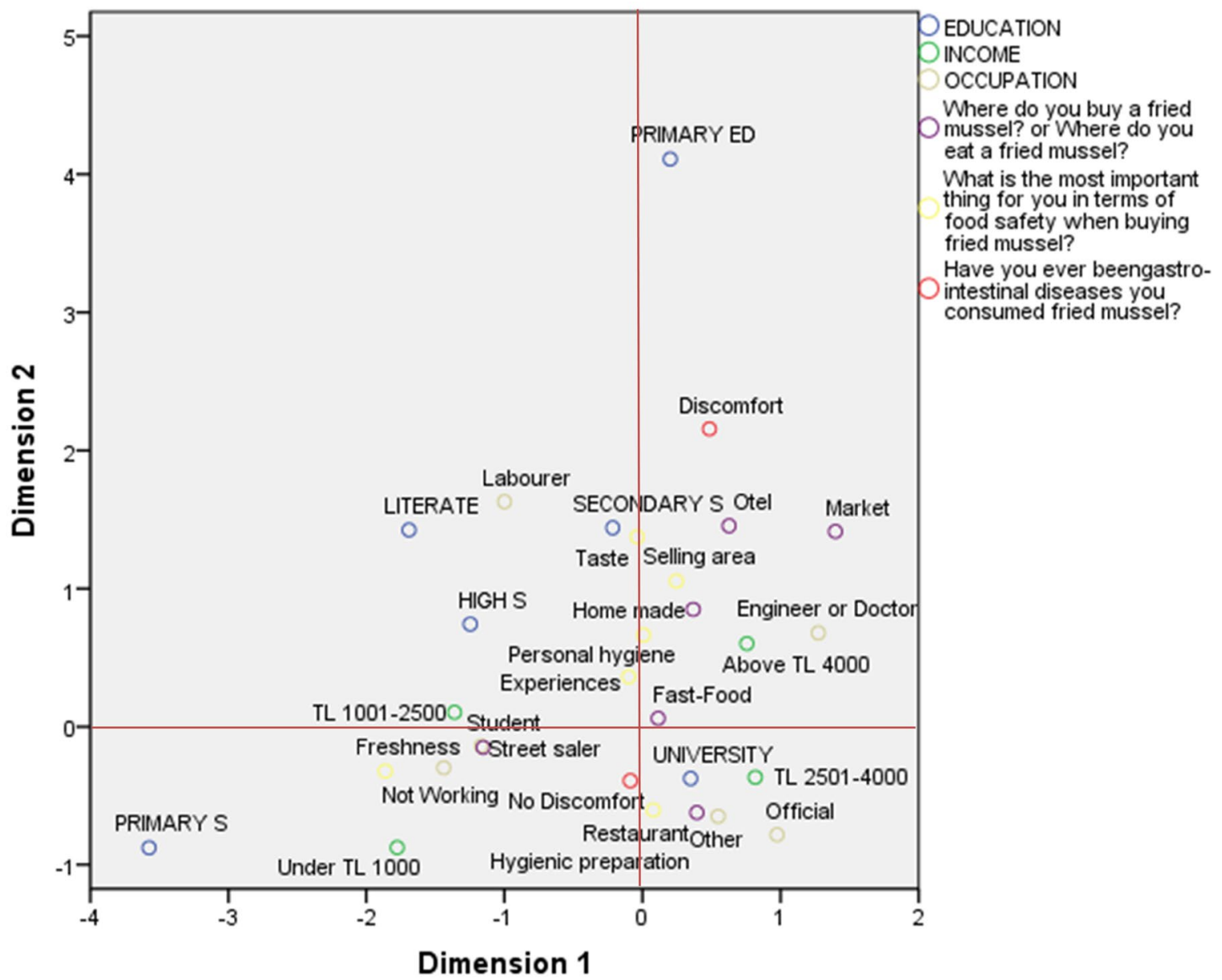

Figure 4. Two dimensional multiple correspondence analysis map for 3 categorical variables (Education, Income, Occupation, Q16, Q17, Q20) 
Table 6 presents the results of discrimination measures for dimensions and variables. As a result of analysis, the inertia values are obtained by 0.351 for Dimension 1 and 0.332 for Dimension 2. According to these values, the graphical representation given in Figue 1 can be said to have a good fit between the categories with a total variance ratio of $68.3 \%$. When discreteness measures which are called as squared correlation in Table 6 are examined, it is seen that income, occupation and Q16 variables contribute a great deal to explain the first dimension, also, in the explanation of the second dimension, education, Q17 and Q20 are very important variables. They have a good contribution for Dimension 2 .

Table 6. Discrimination measures for dimensions and variables (Education, Income, Occupation, Q16, Q17, Q20)

\begin{tabular}{|c|c|c|}
\hline Variables & Dimension 1 & Dimension 2 \\
\hline Education & 0.291 & 0.366 \\
\hline Income & 0.692 & 0.128 \\
\hline Occupation & 0.664 & 0.376 \\
\hline $\begin{array}{l}\text { Q16. Where do you buy a } \\
\text { fried mussel? or Where } \\
\text { do you eat a fried mus- } \\
\text { sel? }\end{array}$ & 0.357 & 0.294 \\
\hline $\begin{array}{l}\text { Q17. What is the most im- } \\
\text { portant thing for you in } \\
\text { terms of food safety when } \\
\text { buying fried mussel? }\end{array}$ & 0.078 & 0.341 \\
\hline $\begin{array}{l}\text { Q20.Have you ever } \\
\text { beengastro-intestinal } \\
\text { diseases you consumed } \\
\text { fried mussel? }\end{array}$ & 0.025 & 0.487 \\
\hline
\end{tabular}

When Figure 4 is examined, it is clearly seen that the engineers or doctors from the respondents participating in the survey whose incomes are above TL 4000 have reached fried mussel through hotel, market or home made and discomfort. Under TL 1000 and TL 1001-2500 students and not-working responders usually buy fried mussel from street vendors and are usually Non-Discomfort. It is seen that the university educated official and others with a TL 2501-4000 income prefer to buy fried mussel generally from the resteurants and hygienic preparation, also, they are important for them in terms of food safety. Also, in Figure 4, the primary school and primary education categories seem to be far from the origin. This indicates that the marginal frequencies of these categories are less than the others.

MCA analysis was also performed for different combinations of other questions. However, these findings were not included in the study as graphical approaches with low explanatory rates were obtained.

\section{Conclusion}

We have used multiple correspondence analysis (MCA) method in determining food safety perception of customers in a food safety survey. Graphical interpretations which are obtainded by MCA of the food safety survey data provides vital information. As we discussed above that MCA was a method for exploring relations between categorical variables in dataset.

As a result of research, it was determined that of respondents under the age of 30 do not have knowledge about food safety, but respondents over the age of 30 has knowledge about food safety. Also, the respondents in the $45+$ age group think that fried mussel is healthy, while the 30-44 age group clearly think that they are not healthy. Overall respondents have different views of different sea products consumption, sales locations, hygienic conditions and food safety.

\section{Compliance with Ethical Standard}

Conflict of interests: The authors declare that for this article they have no actual, potential or perceived the conflict of interests.

Financial disclosure: This research has been supported by Sinop University Scientific Research Projects Coordination Unit. Grant/ Project Number: TOY 1901-16-44, 2016.

Ethics committee approval: No ethics committee approval is needed.

\section{References}

Abdi, H., Valentin, D. (2007). Multiple correspondence analysis. Encyclopedia of Measurement and Statistics, 651657.

Alfiero, S. Giudice, A.L., Bonadonna, A. (2017). Street Food and İnnovation: the food truck phenomenon. British Food Journal, 119(11), 2462-2476. https://doi.org/10.1108/BFJ-03-2017-0179

Benze'cri, J.P. (1969). Statistical analysis as a tool to make patterns emerge from data. In: Watanabe, S. (Ed.) Methodologies of Pattern Recognition (pp. 35-74). Academic Press, New York.

https://doi.org/10.1016/B978-1-4832-3093-1.50009-2

Benze'cri, J.P. (1992). Correspondence analysis handbook. CRC Press, Pages 1-8, ISBN: 9780824784379.082478437 
Bindu, J., Srinivasa- Gopal, T.K., Unnikrishnan -Nair, T.S. (2004). Ready-to-eat mussel meat processed in retort pouches for the retail and export market. Packaging Technology and Science, 17(3), 113-117.

https://doi.org/10.1002/pts.637

Bindu, J, Ravishankar C.N, Srinivasa- Gopal, T.K. (2007). Shelf life evaluation of a ready-to-eat black clam (Villorita cyprinoides) product in indigenous retort pouches. Journal of Food Engineering, 78(3), 995-1000.

https://doi.org/10.1016/j.jfoodeng.2005.12.040

Bindu, J., Mallick, A.K., Gopal, T.K.S. (2014). Thermal processing of fishery products in flexible and rigid containers. Fishery Technology, 51, 137-148.

Clausen, S.E. (1998). Applied Corrispondence Analysis. Sage, London, Pages 37-39, ISBN: 9780761911159

https://doi.org/10.4135/9781412983426

FAO (2011). Street foods: the way forward for better food safety and nutrition. Global forum on Food Security and Nutrition. Summary discussion no. 73. From 26 September to 21 October 2011. http://www.fao.org/fsnforum/sites/default/files/files/73 street foods/sum-

mary 73 street food_en.pdf (accessed date: 02.06.2018).

Greenacre, M.J. (1988). Correspondence analysis of multivariate categorical data by weighted least-squares. Biometrika, 75, 457-467.

https://doi.org/10.1093/biomet/75.3.457

Greenacre, M. (2017). Correspondence analysis in practice. CRC press, Pages 137;241, ISBN: 9781315369983

https://doi.org/10.1201/9781315369983

Greenacre, M.J., Blasius, J. (1994). Correspondence Analysis in The Social Sciences, London, Academic Press, Pages 30-50, ISBN: 9780121045708

Greenacre, M., Blasius, J. (2006). Multiple correspondence analysis and related methods. Chapman and Hall/CRC, Pages 41-45, ISBN: 9780429141966

https://doi.org/10.1201/9781420011319

Gülse-Bal, H.S. Göktolga, Z.G., Karkacier, O. (2006). The examination of consciousness level of consumers abaout food safety (A case of Tokat province). Tartm Ekonomisi Dergisi, $12(1), 9-18$.
Hill, M.O. (1974). Correspondence analysis: A neglected multivariate method. Applied Statistics, 23(3), 340-54. https://doi.org/10.2307/2347127

Husson, F., Josse, J. (2014). Visualization and verbalization of data. Multiple Correspondence Analysis. IJ Blasius, and M. Greenacre, eds. Chapman \& Hall/CRC, UK, Pages 165219, ISBN 9781466589803

https://doi.org/10.1201/b16741

Husson, F., Josse, J., Le, S., Mazet, J., Husson, M.F. (2018) Package 'FactoMineR'. https://cran.r-project.org/web/packages/FactoMineR/FactoMineR.pdf (accessed date: 01.02.2018).

Kocatepe, D., Taşkaya, G., Turan H., Kaya, Y. (2016). Microbiological investigation of wild. cultivated mussels (Mytilus galloprovincialis L.1819) and stuffed mussels in SinopTurkey. Ukranian Food Journal, 5(2), 299-305. https://doi.org/10.24263/2304-974X-2016-5-2-9

Kocatepe, D., Tirll, A. (2015). Healthy nutrition and traditionals foods. Journal of Tourism and Gastronomy Studies, 3(1), 55-63.

Kocatepe, D., Keskin, İ., Kaya, Y. (2019). The Effect of Frying-the Chemical, microbiological, and acrylamide composition of mussels as a street food. Journal of Aquatic Food Product Technology, 28(1), 117-128.

https://doi.org/10.1080/10498850.2018.1563260

Le Roux, B., Rouanet, H. (2010). Multiple correspondence analysis (Vol. 07- 163). Sage. Los Angeles, London, New Delhi Pages 34-61, ISBN: 9781412968973

https://doi.org/10.4135/9781412993906

Lebart, L., Morineau, A., Warwick, K. (1984). Multivariate Descriptive Statistical Analysis. Correspondence Analysis and Related Techniques for Large Matrices. Wiley, New York, Pages: xvi +231

https://doi.org/10.1002/asm.3150050207

Marras, S., Companion, M., de Cassia Vieira Cardoso, R. (2014). Street Food Culture, Economy, Health and Governance. Routledge, p. 275, ISBN: 978-1-13-802368-0

Nishisato, S. (1980). Analysis of Categorical Data: Dual Scaling and its Applications. University of Toronto Press, Toronto Pages 74-97, ISBN: 978-1-4875-7890-9

https://doi.org/10.3138/9781487577995 
Ohiokpehai, O. (2003). Nutritional aspects of street foods in Botswana. Pakistan Journal of Nutrition, 2(2), 76-81. https://doi.org/10.3923/pjn.2003.76.81

Şahin, A., Meral, Y. (2012). Turkey's geographical marking and local products. Türk Bilimsel Derlemeler Dergisi, 5(2), $88-92$.

Steyn, N.P., Mchiza, Z., Hill, J., Davids, Y.D., Venter, I., Hinrichsen, E., Opperman, M., Rumbelow, J., Jacobs, P. (2013). Nutritional contribution of Street foods to the diet of people in developing countries: a systematic review. Public Health Nutrition, 19(06), 1-12.

Taşdan, K., Albayrak, M., Gürer, B., Özer, O.O., Albayrak, K., Güldal, H.T. (2014). Geleneksel gidalarda tüketicilerin gıda güvenliği algısı: Ankara ili örneği. Davraz
Kongresi. Sözlü Bildiri. Http://yucita.org/uploads/yayinlar/diger/makale/Geleneksel_Gdalarda_Tuketicilerin_Gda_Guvenlii_Algs.pdf (accesed date: 17.05.2018).

Turan, H., Altan, C.O., Kocatepe, D., Ceylan, A. (2015). Quality of lakerda (dry salted bonito) madewith different technics in Sinop region. Ukranian Journal of Food Science, 3(1), 6-12.

Weller, S.C., Romney, A.K. (1990). Metric Scaling. Correspondence Analysis. Sage, London, Pages 2-7, ISBN: 9780803937505

https://doi.org/10.4135/9781412985048

Young, F.W. (1981). Quantitative analysis of qualitative data. Psychometrika, 46, 357-387.

https://doi.org/10.1007/BF02293796 